\title{
Glutamate: Susceptible and Vital Doorkeeper
}

\author{
Supriya Chavan* and Kedar Prabhavalkar \\ Bhanuben Nanavati College of Pharmacy, India
}

Submission: July 07, 2018; Published: August 17, 2018

*Corresponding author: Supriya Chavan, Bhanuben Nanavati College of Pharmacy, India, Email: supriya_chavan1991@yahoo.in

\begin{abstract}
Stress is relatively common medical condition which is many times considered as nonmedical common physiological condition by most the population. However, this article is focused on the severity of chronic stress which is like the state of drug addiction. Chronic stress shares similar pathways of neurotoxicity as psychostimulants.
\end{abstract}

Keywords: Stress; Drug addiction; Neurotoxicity; Psychostimulants

Abbreviations: HPA: Hypothalamic-Pituitary-Adrenal Axis; CNS: Central Nervous System; CRH: Corticotrophin Releasing Hormone; AVP: Arginine Vasopessin; PVN: Paraventricular Nuclei; NE: Nor-Epinephrine; LC: Locus Coeruleus; ACTH: Adrenocorticotropic Hormone; DA: Dopamine, NG: Nerve Growth Factor; BDNF: Brain Derived Neurotrophic Factor; GLU: Glutamate

\section{Introduction}

\section{The stress system}

Stress is a state which threatens homeostasis of neurochemicals, caused by an intrinsic or extrinsic adverse forces (stressors) and is counteracted by an intricate repertoire of physiological and behavioural responses [1]. Although the entire Central Nervous System (CNS) is directly or indirectly involved in conserving the overall body homeostasis, specific areas of the brain have critical and distinct roles in stress response. Following regions of CNS specifically reported in stress pathophysiology, the central components of stress system are located in the hypothalamus, the brainstem, include paravacecullar corticotrophin releasing hormone (CRH), arginine-vasopessin (AVP), neurons of paraventricular nuclei (PVN) of hypothalamus, the CRH neurons of paragigantocellular and parabranchial nucli of the medulla, the locus coeruleus (LC), catecholaminergic, norepinephrine (NE)-synthesizing cell groups of the medulla, pons (central sympathetic nervous system) [2]. The peripheral limbs of hypothalamic-pituitaryadrenal (HPA)axis, together with efferent sympathetic nervous system/ adrenomedullary system creates the peripheral component of this interconnected system [3].

Hypothalamic-Pituitary-adrenal axis (HPA) and stress: The HPA axis is a vital component of both central and peripheral limb of the stress system [4]. HPA's integrity and precise regulation of its function are essential characteristic of the successful adaptive response to any stressor [5]. Corticotropin releasing hormone ( $\mathrm{CRH})$ is one of the important hormone involved in stress pathology acts through HPA axis. It is released into the hypophyseal portal system and acts as a principle regulator of adrenocorticotropic hormone (ACTH) secretion [6]. While the AVP acts as a potent synergistic factor to CRH with a little ACTH secretagogue activity by itself $[7,8]$. Under non-stressful conditions, both CRH and AVP are secreted into portal system in circadian and highly concordant pulsatile fashion $[9,10]$. The HPA axis activity is characterised not only by typical circadian rhythm but also by a pattern of discrete pulsatile release of glucocorticoids, with pulse of production for every 1-2 hours [11]. Thus, the circadian release of CRH/AVP/ACTH in their distinctive pulsatile manner appears to be controlled by one or more CNS pace makers. These diurnal deviations are disturbed by alterations in lighting, feeling and physical activity patterns, whilst they are disrupted when stressor is imposed [12]. During acute stress, the amplitude and synchronisation of both $\mathrm{CRH}$ and AVP secretory pulses increases, with additional recruitment of PVN, CRH and AVP secretion [12]. The adrenal cortex constitutes the peripheral target organ of the pituitary derived circulating ACTH. Current evidences primarily suggest that, the adrenal cortisol secretion is further regulated by hormones and cytokines coming from the adrenal medulla or the systemic circulation, and by neuronal signals via autonomic innervation of the adrenal cortex [13].

Psychostimulants and neurotoxicity: Psychostimulants are essentially 'CNS stimulants' [14]. The mistreatment is a major public issue because it is associated with serious health complications; including devastating consequences of CNS. The 
neurotoxic effects of these drugs have been extensively studied. The neuronal function and neurotransmission in the brain can be altered by the Psychostimulant which has the strongest ability to do so. It is known that these substances increase extracellular level of several neurotransmitters including Dopamine (DA), Serotonin (5-HT) and norepinephrine by competing with monoamine transporters; this can further induce physical tolerance and dependence. Further to these findings, it also suggests that psychostimulants may damage brain neurons through various mechanisms [14]. In recent years it has been demonstrated that almost all psychostimulants are able to affect the neurotrophins in peripheral and central nervous system. Altered neurotrophins may participate in the pathogenesis of psychiatric disorders, which is a common reason of these disorders in drug users [15]. Neurotrophins such as nerve growth factor (NG) and brain derived neurotrophic factor (BDNF) have relevant action neurons involved in psychostimulant action such as DA, serotonin and play dual roles: first, in neuronal survival and death; second in activity dependent plasticity [15]. In this review, we will focus on similarities of mechanisms involved in psychostimulant induced neurotoxicity and stressor induced neurotoxicity.

\section{Discussion}

\section{Stress and neurotoxicity/ psychostimulants and neurotoxicity}

A peculiar cause of psychostimulant induced neurotoxicity is apoptosis. Psychostimulants increases extracellular concentration of Glutamate (GLU) [16]. It has been demonstrated that spectrin proteolysis resulting from activation of glutamate receptors, is through influx of calcium (ca2+) ions and subsequent activation of the calcium dependent proteases such as calpain and caspaces which are established pathophysiology of neurotoxicity involved in traumatic brain injury. The psychological chronic stress is being associated by elevations in GLU; Furthermore, it's reported in many researches that an increase in extracellular glutamate in various brain regions after exposer to various stressors are attenuated by adrenaleoctomy. Furthermore, an elevation in glucocorticoids and extracellular glutamate due to chronic stress leads to spectrin proteolysis in the hippocampus produced by kinetic acid [17].

\section{Conclusion}

Many researches have demonstrated an interdependent relationship between unpredictable chronic stress induced an augmentation of extracellular GLU and psychostimulant induced GLU response shares a similar pathological pathway. Stress has a high transitional value for the targeted prevention and /or management of broad spectrum of clinical conditions. It is now recognized that a strong interdependent link exists between neurobehavioral/phychoemotional stress and certain classic disease states relating to autoimmunity, metabolic disorders [18]. Understanding the organization and assimilation of specific stress system pathways and neurochemical networks which facilitates these links constitutes a significant step forward in exploring the pathogenesis of stress related complications [19]. As of now a persuasive body of experimental, epidemiologic and clinical evidence strongly supports the significant impact of acute and chronic stress on both physical health and emotional well-being, highlighting the need of further ongoing research in this field.

\section{References}

1. Chrousos GP (2009) Stress and disorders of the stress system. Nat Rev Endocrinol 5(7): 374-381.

2. Valentino RJ, Foote SL, Aston Jones G (1983) Corticotropin-releasing factor activates noradrenergic neurons of the locus coeruleus. Brain Res 270(2): 363-367.

3. Mc Ewen BS (2007) Physiology and neurobiology of stress and adaptation: central role of the brain. Physiol Rev 87(3): 873-904.

4. Hardy K, Pollard H (2006) The organisation of the stress response, and its relevance to chiropractors: a commentary. Chiropr Osteopat 14: 25.

5. Chrousos GP (1992) Regulation and dysregulation of the hypothalamicpituitary-adrenal axis. The corticotropin-releasing hormone perspective. Endocrinol Metab Clin North Am 21(4): 833-858.

6. Tsigos C, Chrousos GP (1994) Physiology of the hypothalamic-pituitary-adrenal axis in health and dysregulation in psychiatric and autoimmune disorders. Endocrinol Metab Clin North Am 23(3): 451-466.

7. Fuller RW (1992) The involvement of serotonin in regulation of pituitary-adrenocortical function. Front Neuroendocrinol 13(3): 250-270.

8. Sigos CT, Kyrou I, Kassi E (2006) Stress, endocrine physiology and pathophysiology. South Dartmouth, Massachusetts, USA.

9. Lim CT, Khoo B (2014) Normal physiology of ACTH and GH release in the hypothalamus and anterior pituitary in man. South Dartmouth, Massachusetts, USA.

10. Marshall J (2002) Control of pituitary hormone secretion-role of pulsatility. In: Besser G, Thorner M, (Eds.), Comprehensive Clinical Endocrinology. Edinburgh, UK.

11. Doniach I (1985) Histopathology of the pituitary. Clin Endocrinol Metab 14(4): 765-789.

12. Herman JP, Mc Klveen JM, Ghosal S (2016) Regulation of the hypothalamic-pituitary-adrenocortical stress response. Compr Physiol 6(2): 603-621.

13.Edwards AV, Jones CJ, Anat J (1993) Autonomic control of adrenal function. J Anat 183(pt 2): 291-307.

14.Lin Z, Canales JJ, Björgvinsson T, Thomsen M, Qu H, et al. (2012) Monoamine transporters: vulnerable and vital doorkeepers. Prog Mol Biol Transl Sci 98: 1-46.

15.Steketee JD, Kalivas PW (1991) Sensitization to psychostimulants and stress after injection of pertussis toxin into the A10 dopamine region. J Pharmacol Exp Ther 259(2): 916-924.

16.Angelucci F, Ricci V, Spalletta G, Caltagirone C, Mathé AA, et al. (2009) Effects of psychostimulants on neurotrophins implications for psychostimulant-induced neurotoxicity. Int Rev Neurobiol 88: 1-24.

17.Popoli M, Yan Z, Mc Ewen B, Sanacora G (2011) The stressed synapse: the impact of stress and glucocorticoids on glutamate transmission. Nat Rev Neurosci 13(1): 22-37.

18.Tata DA, Yamamoto BK (2008) Chronic Stress Enhances Methamphetamine-Induced Extracellular Glutamate and Excitotoxicity in the Rat Striatum. Synapse 62(5): 325-336.

19.Das S, Barnwal P, Ramasamy A, Sen S, Mondal S (2016) Lysergic acid diethylamide: a drug of 'use'? Ther Adv Psychopharmacol 6(3): 214228. 


\section{Psychology and Behavioral Science International Journal}

(C) This work is licensed under Creative BY DOI: 10.19080/PBSIJ.2018.09.555772
Your next submission with Juniper Publishers will reach you the below assets

- Quality Editorial service

- Swift Peer Review

- Reprints availability

- E-prints Service

- Manuscript Podcast for convenient understanding

- Global attainment for your research

- Manuscript accessibility in different formats ( Pdf, E-pub, Full Text, Audio)

- Unceasing customer service

Track the below URL for one-step submission https://juniperpublishers.com/online-submission.php 